\title{
Mexico Needs to Proactively Educate Maquiladora Workers
}

\author{
Dr. Allan Beck ${ }^{1, *}$ \\ ${ }^{1}$ School of Business, University of Phoenix, Phoenix, AZ 85034, USA \\ *Correspondence: School of Business, University of Phoenix, 3157 E. Elwood, Phoenix, AZ \\ 85034, USA \\ Tel: 956-457-2591Ｅ-mail: mcbek@email.phoenix.edu
}

Received: November 26, 2012 Accepted: January 24, 2013 Published: March 15, 2013

doi:10.5296/rae.v5i1.3286ＵRL: http://dx.doi.org/10.5296/rae.v5i1.3286

\begin{abstract}
Mexico is not known for an outstanding public education system. Rankings are less than needed to advance the manufacturing sector and move into a more competitive high-tech model to support the needs of North America and fight off the constant threat of outsourcing. In the study described herein a clear deficiency in educating the workforce was a lack of bringing education to the industrial parks and the workforce that requires upgrading to compete on a global stage. Competitiveness and innovation are dominant themes of successful workforce improvement efforts. The government and educational institutions need to understand the limitations and restrictions of potential students and offer classes close to the workplace and, specifically, in the maquiladora industrial parks.
\end{abstract}

Keywords: Mexico; maquiladora; education; technology; manufacturing; strategy for manufacturing; Delphi study 


\section{Introduction}

Despite a rich tradition of manufacturing, especially since the end of the Bracero program in the United States, Mexico historically acquired manufacturing work based on a low-cost and low-wage model, but the country has failed to evolve at a pace to keep it the source of choice for high-tech manufacturing supporting the requirements of North America. The Bracero program was originally set up to help with a labor shortage in the United States during World War II and continued to run until 1964. Mexico’s Border Industrialization Program followed and the maquiladora program officially began in 1971 creating jobs and providing a livelihood for many Mexican families (Eldenburg, Roman \& Teruya, 2007). The series of activities utilized to attract industry into Mexico established manufacturing as an important component in Mexico's economy, and the attractive feature for companies locating a maquiladora operation was to only pay tax on the value-added portion of the goods shipped out of Mexico. Since the onset of the maquiladora program, the tax situation made Mexico an obvious choice for many global entities.

With a favorable location and a North American Free Trade Agreement membership with the United States and Canada, Mexico is positioned to become the natural supplier of technology for the region. The regionally low labor cost still attracts some business from within North America, but wages alone cannot ensure a sourcing decision. A lack of education and experience have pushed sourcing decisions off-shore and overseas, primarily to Asia. Mexico needs to put an emphasis on furthering the education of manufacturing sector workers so that manufacturing can embrace technology.

Many maquiladora jobs have disappeared since 2000, and it may be time to work toward developing a new strategy, as the low-cost and low-wage model is not always competitive when compared with other producing areas of the world. The highest concentration of lost jobs in maquiladoras was from 2000 to 2003, and there has been slow growth since, but manufacturing jobs are still at a lower level than the peak. A large segment of the population continues to suffer as a result of the negative growth in manufacturing (Mendoza, 2010). Infrastructure deficiencies like a poor educational system, and other factors like globalization and financial downturns have left the traditional low-cost maquiladora model outdated and uncompetitive (Hadjimarcou, Brouthers, McNicol \& Michie, 2013).

Mexico needs to establish a long-term strategy that will allow it to compete for high technology work because Mexico will need to lower costs by automating and performing tasks considered high-tech and advanced compared to the original maquiladora model. An increased effort on the part of the Mexican government to create policies that will enhance competitiveness and innovation in manufacturing (Carrillo, 2009). Mexico will need to emphasize and prioritize public education and find a way to provide additional university-level education to workers that only possess a high school education. Many Mexican workers only have the compulsory 9th grade education when entering the workforce and the only enhancement comes in the form of company sponsored training. The training is specific to a particular job or function and not in the realm of what education can produce. 


\section{Literature Review}

Between October 2000 and December 2003, Mexico lost 300,000 jobs and over 800 maquiladora factories because of the growing presence and surge of China's exports (Sargent \& Matthews, 2009). The Chinese option was an interesting development and should have spurred Mexico into action. Mexico was losing business to China by trying to compete on a low-cost and low-wage platform. Mexico was increasingly coming up short on the decisions to move or build in Mexico. The interesting part of the China strategy was a low-cost and low-wage strategy combined with a technology-based manufacturing option, as China had completed a strategy of industrial upgrading and could compete on both a high tech and low tech platform (Sargent \& Matthews, 2009). The exodus of business to China left Mexico with a smaller maquiladora base and no solid strategy to combat the erosion of the manufacturing base. Maquiladoras have been an important part of the Mexican economy and manufacturing has supported a majority of workers in northern border cities since shortly after the Bracero, or guest worker program ended in the United States in 1964 (Vogel, 2007).

Mexico and Turkey tied for last place in the Organization for Economic Cooperation and Development (OECD) ranking of elementary science scores and a correlation to the results can be tied to an underfunding of education dedicated to the sciences (Menchaca-Rocha, 2010). The OECD ranked Mexico second-last in government spending in science and last in scientists per capita (Menchaca-Rocha, 2010). Mexico also ranks low using competitiveness metrics. The Economist conducted a study in 1997 and Mexico ranked 44th in the world in competiveness (Carrillo, 2009). The highest score for government policies was 34th (Carrillo, 2009). Mexico's uncompetitive nature has changed the context in which maquiladoras exist (Carrillo, 2009). The priorities must change if Mexico hopes to build a technology-based manufacturing base to compete in a complex world.

A partnership of industry, education, and government must be formed to create a vision and focus for advancing manufacturing. A clear vision of the future must be jointly viewed and uniformly pursued in cooperation and solidarity to prevent fragmentation and to meet the challenges of a sustainable global approach in the role of manufacturing (Hernandez et al., 2010). The sectors play an important role in implementing a national strategy for a knowledge-based economy, and by combining efforts; critical decisions can be positively influenced regarding spending for education. Industry, education, and government must work together to upgrade and create an innovative workforce. Mexico cannot afford to continue to ignore the recommendations of OECD without the risk of permanently eroding the manufacturing base of the economy (Menchaca-Rocha, 2010). Much of the lack of competitiveness and innovation is attributed to a weak long-term government economic vision, a lack of economic growth, poor financing, a lack of attention to strategic opportunities, and a poor national research system (Carrillo, 2009).

Perhaps a source of resources may reside in efforts to partner with stakeholders on the U. S. side of the border. Leaders on both sides of the border could collaborate to expand the high-technology initiative. The University of Texas Pan American, in Edinburg, Texas, United States, graduates engineers and other professional and technical personnel who go to 
work directly into the Mexican maquiladoras.

Operating in a high-technology manufacturing environment requires focusing on technology and processes (O’Sullivan, Rolstadas \& Filos, 2011). To run and upgrade systems requires engineers and other technical personnel in a changing environment that takes dialog between educators and manufacturing organizations to maintain a robust curricula as changes occur. Labor intensive, or low-technology manufacturing will reside in low wage economies, but high technology, which creates the majority of wealth creation activities requires a high skilled stable workforce (O’Sullivan et al., 2011). A high skilled workforce requires raising people’s skills through education (O’Sullivan et al., 2011).

Over a million Mexican citizens rely on maquiladoras for sustaining themselves and families in over 3,000 manufacturing plants (Rosenberg, 2013). Jobs have been lost and factories closed in part due to a lack of adequate education, poor governmental infrastructure, and a lack of coordination of interested stakeholders. Government should lead the efforts to save manufacturing jobs because so much of its population relies on the sector for a livelihood.

Israel had a similar problem, but an innovative economy emerged in the period of 1990 2000 (Avidor, 2011). The preconditions and the change took 30 years, but the deliberate actions of the government and other stakeholders, which also included a robust education and training infrastructure, enabled Israel to gain better access to manufacturing opportunities (Avidor, 2011). Knowledge was acquired by sponsoring conferences and consortiums between academia and industry (Avidor, 2011).

Finland ranked behind the other Scandinavian countries in terms of workplace innovation and was not able to cope with economic downturns, technological improvements, and globalization (Alasoini, Ramstad, Heikkila, \& Ylostalo, 2010). A deliberate educational process over a period of years has shown workplace and management improvement as the Finnish people have learned to utilize external resources to acquire new knowledge (Alasoini et al., 2010). A weakness uncovered in a study by Alasoini, Ramstad, Heikkila and Ylostalo (2010) was that employer paid training fails to focus on issues to help organizations and employees succeed in the world (Alasoini et al., 2010). Industry, educators, and the government working together can jointly set priorities and agree on the correct curricula to better compete with global forces.

\section{Research Method}

A Delphi study methodology was used with a 21-person panel of experts consisting of seven educators, seven industry, and seven governmental individuals. The research question was to understand what each of the three groups; education, industry, and government can do to make the region viewed as a favorable alternative for outsourcing into Mexico or expanding to the region. China and other low-cost regions of the world were winning contracts and growing. The trend to take manufacturing to Asia was costing Mexico jobs. The study concentrated on Reynosa, Tamaulipas, Mexico, and included participants cognizant of the maquiladora situation throughout the region. All participants were required to have at least 
five years of direct maquiladora experience, but the final panel had an average of more than 13 years per participant. Experts on maquiladora operations provided a collective strategy of improved education through a series of iterative responses. The responses of the experts answered the following research question:

RQ 1: What does the training and education system need to do to support the needs of manufacturing and make the region more attractive to new opportunities?

A pilot study with two rounds was employed to achieve face validity with a three-person panel of experts. The pilot study consisted of one each on the panel of experts from industry, education, and government. The pilot study identified the needs of increasing internships, partnering with companies, and developing customized training programs. The themes that emerged from the pilot study were surface-related, and it took the broader panel of experts in the main study to put a more succinct definition of the roles of industry, education, and the government. One of the most obvious needs identified in the findings was the need to expand education and make it more accessible to the manufacturing employee. Face validity was achieved because all participants in the pilot study understood the process, agreed it would answer the research questions, and agreed the method was appropriate to attain success. Participants in the pilot study understood the open-ended questions asked and did not have any suggestions to change or improve the process.

The pilot study allowed participants to read all responses and rank the responses in order of importance. The pilot study allowed participants to ask for clarification if a term or comment was not understood. One participant took advantage of the opportunity to ask and sought a clearer definition of a particular term. The participant who sent in the term in response to an open-ended question was asked by the researcher to better define, and when received; the expanded definition was sent out to all to make sure all participants had the same understanding. $100 \%$ participation and $100 \%$ agreement or consensus was realized in the pilot study.

The Delphi study employed an iterative process of open-ended questions with the panel of experts on maquiladoras. The process was Internet-based and the open-ended questions sent out and retrieved through e-mail. The main study consisted of three rounds of open-ended questions. Twenty-one experts; seven from industry, education, and government participated in the main study. Stakeholders from the three sectors participated on the panel, but panel members did not know who else was on the panel. Only the researcher knew the panel's exact composition in an effort to reduce or eliminate any bias from a dominant panel member. The anonymity allowed all to freely express thoughts and add insight without fear of ridicule or dominance by an outspoken panel member. The objective was to develop a meaningful manufacturing model factoring in all opinions from the entire panel.

The first iterative question in the main study was a series of questions asking the panel of experts for opinions on the needs of industry, education, and government and what could be done by each in support of improving opportunities. The second round of questioning the panel was designed to bring the consensus closer by asking panel members to consider economic factors and identify what internal and external factors made a difference in 
increasing manufacturing activity for maquiladoras. The open-ended question in round three was designed to test the strength of the consensus among the panel of experts. The question started by summarizing the conclusions of the joint panel to-date. Following the summation the panel was asked if there was agreement with the summary, agreement with additional items factored in, or disagreement.

In the main study, the experts wanted better access to educational and training resources by identifying the need for satellite centers close to industrial parks, and a need to ask the Mexican government to put a higher priority on educating more of the workforce through the public education system. Many maquiladora workers rely on public transportation or private busses contracted by the employer to get to and from the workplace. Even if interested in furthering the level of education, a worker may find it impossible to attend a class if required to travel to another location and attend class in an established educational facility outside the immediate venue. Transportation becomes a real issue when relying on a company or city bus. Many of the Fortune 500 companies would be happy to assist in the process by providing the transportation for individuals interested in advancing collective knowledge base and individual careers.

Educational providers need to be informed of the worker transportation limitations and increase the influence institutions have on shaping the industrial base by making educational access available to the masses regardless of transportation issues. Rather than simply offer the correct curricula and expect interested workers to find the transportation required to attend institutions; the institutions of higher education need to construct facilities near the workplace for easy worker access. The government should encourage worker access to improve the movement of industry into a different high-technology business model.

The government should partner with educators and industrial organizations by providing incentives to establish a presence in the industrial parks. Agreements with companies could even allow educators to come into an industrial setting and use the industrial organization's classroom or conference room to provide the education. Education will drive the effort and industry with the cooperation of government should work together to facilitate the best learning experience in advancing the unconventional model to support manufacturing.

A theme that emerged from the study emphasized the need for educators and government working together to provide the programs and educate workers with the knowledge needed to advance manufacturing to a new level of competence. The heightened competence level should make it a viable option for companies outsourcing or expanding. Clearly a major finding identified in the study was a need for institutions of higher learning to place accommodations of education in locations convenient for workers so that a desire to more into a high tech model may be realized. Mexico should place education as a higher priority for today's workers, and as a means to sustain manufacturing operation and expansion.

\section{Findings}

The main study built on the findings from the pilot study, and because of the depth of 
experience that a 21-person panel of experts brought into the study, recommended taking education into the work environment. The specific findings suggested locating satellite teaching centers near industrial parks for easy-access to classes and encouraging policies to improve and provide education beyond the ninth grade. Clearly the responsibility falls in the realm of the government, but the education community can be proactive in supporting the needs of industry. The panel of experts identified educating future workers to be innovative and technology-focused. If the focus of educators, industry, and the government become single-minded and a clear vision emerges, the new strategy and approach may lead to a future of high technology which can improve the overall plight of the maquiladora worker because the high-tech worker is typically a higher wage earner.

Many maquiladora workers have a hard time supporting themselves and their families and a broader and deeper education system could help to ease the financial struggles for the average family. Since the onset of the North American Free Trade Agreement real wages for $10 \%$ of the maquiladora workers have decreased and border wages are $25 \%$ lower than in other parts of the country (Ki, 2010). If educators, industry, and the government all get behind an effort to provide additional educational opportunities for the average factory worker, the middle class may grow and help to spur the economy and lift individual standards of living.

Mexico has done a poor job developing the education system, and has few university graduates with good English-speaking skills, thus finding and attracting the necessary workers to support higher value-added jobs is more difficult in Mexico than in other locations (Farrell, Puron, \& Quesada, 2007). Educated and English-speaking maquiladora workers could prove to be a competitive advantage when supplying goods and services to North America. Mexico needs to move education up on the list of country priorities in order to boost manufacturing capabilities because of a low suitability for jobs frustrated by the deficiencies in the education system (Farrell et. al., 2007). If manufacturing is to remain a priority for jobs in the economy of Mexico, then educational changes to support the new manufacturing model may prove interesting.

\section{Discussion}

Hernandez, Noruzi, and Sariolghalam (2011) discuss a changing global international educational perspective and note that educational institutions need to connect the workforce with a level of competency to conduct business on a global scale with negative consequences if the challenges are not met. Perhaps making educational resources more accessible to the workforce will assist Mexico in meeting the challenge of providing maquiladora workers with the necessary level of education and improving educational priorities. The education system in Mexico is questionable in supporting a technology-based manufacturing model because $30 \%$ of the population over 15 years has not completed elementary school (Najera, 2008). Education is an important consideration according to the panel of experts in the Delphi study to get manufacturing back to the level of importance in the Mexican economy. In the main Delphi study, the panel of experts not only achieved consensus, they were in $100 \%$ agreement on the education issue. 


\section{Conclusion}

Major obstacles in determining Mexico’s readiness to transform itself into a high-technology manufacturing model may be a shortage of data regarding the status of engineering capabilities. Some technology-driven businesses are operating in Mexico, and technology is a model that many Mexican governmental officials and academicians have offered as a means to recapture the lost share of United States imports (Sargent \& Matthews, 2009). Mexico has dropped from 48th to 57th in technology and was 59th of 117 countries in innovation on the United Nations Conference on Trade and Development (UNCTAD) capability index (Sargent \& Matthews, 2008). Education may be the answer for the maquiladoras of the future, but it will take a joint effort on the part of education, industry and government. By prioritizing education, Mexico may be in a position to recapture all lost employment since 2000, and begin a new progression of improved growth.

The best model for success was expressed in the collective opinions of the panel of experts. Not only did the panel reach consensus, the panel was in 100\% agreement that the emphasis on the part of educators and the government working with industry to put together curricula to support technology was needed. Twenty-one experts from industry, education, and government all came together to identify education as a major finding in the study. Mexico should not delay in putting together a plan to support the enhanced project involving educating the manufacturing workers and moving Mexico from the low-tech manufacturing model to a strategy of high-tech manufacturing. By endorsing the findings in the study, Mexico may begin to prioritize education and pull together forces that have the answers regarding the framework for new curricula. Construction of new educational facilities among the maquiladora workers and better access in the industrial parks is a positive first step.

\section{References}

Alasoini, T., Ramstad, E., Heikkila, A., \& Ylostalo, P. (2010). Workplace innovation in Finland: Towards sustainable productivity growth? Vezetestudomany/Budapest Management Review, 41(9), 2-16.

Avidor, J. (2011). Building an innovation economy: Public policy lessons from Israel. Northwestern Law \& Econ Research Paper No. 11-18. Retrieved from http:ssm.com/abstract $=1856603$

Carrillo, J. (2009). Developing the US-Mexico Border Region for a prosperous and secure relationship: Innovative companies and policies for innovation on the US-Mexico Border.

Eldenburg, L., Roman, F., \& Teruya, J. (2007). An Analysis of the effects of maquiladora production on performance. Journal of Accounting, Auditing \& Finance, 22(3), 423-447. Retrieved from Business Source Complete database.

Farrell, D., Puron, A., \& Quesada, I. (2007). Developing Mexico's offshoring opportunity. McKinsey Quarterly, 12-15. Retrieved from EBSCOhost 
Hadjimarcou, J., Brouthers, L. E., McNicol, J. P., \& Michie, D. E. (2013). Maquiladoras in the 21st century: Six strategies for success. Business Horizons, 56(2), 207-217. http://dx.doi.org/10.1016/j.bushor.2012.11.005

Hernandez, J., Noruzi, M., \& Sariolghalam, N. (2010). Multiple intelligences and the future of education in Mexico. Asian Social Science, 6(6), 139-147. Retrieved from EBSCOhost.

Ki, H. (2010). NAFTA is a good deal for workers in North America: Theories and evidence. Proceedings of the Northeast Business \& Economics Association, 517-522. Retrieved from EBSCOhost

Menchaca-Rocha, A. (2010). Science and technology in Mexico. Nature Materials, 9(10), 781-783. http://dx.doi.org/10.1038/nmat2869

Mendoza, J. (2010). The effect of the Chinese economy on Mexican maquiladora employment. International Trade Journal, 24(1), 52-83. http://dx.doi.org/10.1080/08853900903442921

Najera, M. (2008). Managing Mexican workers: Implications of Hofstede's Cultural Dimensions. Journal of International Business Research, 7(2), 107-126. Retrieved from Business Source Complete database

O’Sullivan, D., Rolstadas, A., \& Filos, E. Global educations in manufacturing strategy. Journal of Intell Manufacturing, 22(1), 663-674. http://dx.doi.org/10.1007/s10845-009-0326-2

Rosenberg, M. (2013). Maquiladoras in Mexico. Retrieved from http://geography.about.com/od/urbaneconomicgeography/a/maquiladoras

Sargent, J., \& Matthews, L. (2008). Capital intensity, technology intensity, and skill development in Post China/WTO Maquiladoras. World Development, 36(4), 541-559. http://dx.doi.org/10.1016/j.worlddev.2007.04.015

Sargent, J., \& Matthews, L. (2009). China versus Mexico in the global EPZ industry: maquiladoras, FDI quality, and plant mortality. World Development, 37(6), 1069-1082. http://dx.doi.org/10.1016/j.worlddev.2008.10.002

Vogel, R. (2007). Transient Servitude: The U.S. Guest Worker Program for exploiting Mexican and Central American workers. Monthly Review: An Independent Socialist Magazine, 58(8), 1-23. Retrieved from MasterFILE Premier database.

\section{Copyright Disclaimer}

Copyright reserved by the author(s).

This article is an open-access article distributed under the terms and conditions of the Creative Commons Attribution license (http://creativecommons.org/licenses/by/3.0/). 